Extraction of male steroids and progesterone from water by vegetable oil gels and their determination by partial filling capillary micellar electrokinetic chromatography

\title{
Siren, Heli
}

2019-08

Siren , H \& El Fellah , S 2019 , ' Extraction of male steroids and progesterone from water by vegetable oil gels and their determination by partial filling capillary micellar electrokinetic chromatography ' , Journal of Separation Science , vol. 42 , no. 16 , pp. 2725-2733 . https://doi.org/10.1002/jssc.201

http://hdl.handle.net/10138/315956

https://doi.org/10.1002/jssc.201900139

acceptedVersion

Downloaded from Helda, University of Helsinki institutional repository.

This is an electronic reprint of the original article.

This reprint may differ from the original in pagination and typographic detail.

Please cite the original version. 
1 Title

2 Isolation and $\mathrm{CE}$ determination of male steroids and progesterone from water with

3 vegetable oil gels containing cellulose, cotton, or Kraft lignin.

4 Heli Sirén ${ }^{*}$, Samira El Fellah

5 Department of Chemistry, University of Helsinki, P.O. Box 55, FI-00014 University of Helsinki (FI600560 Helsinki), Finland

7

8

*) Correspondence: Heli Sirén, Faculty of Science, Chemistry, University of Helsinki, P.O. Box 55, FI-00014 University of Helsinki, Finland, heli.m.siren@helsinki.fi

The running title

\section{Isolation of steroids with gels and determination with $\mathrm{CE}$}

Keywords: gels from microemulsion; vegetable oils; cellulose; Kraft lignin; water samples; capillary electrophoresis.

9

0

1

2

3

4

5

6

7

8

9

0



1

\section{Abstract}

Microemulsion (ME) gels were synthetized from vegetable oils of macadamia, linseed, olive, walnut, frying oil (mixture of sunflower, palm, and rapeseed oils), rapeseed, sesame, and coconut. The ME were mixed with acrylamide and carbohydrates including celluloses, cotton, or Kraft lignin. The aim was to compare the sorption properties of the sorbents by using them as adsorbents for steroid hormones in water. Out of the sorbents frying, rapeseed, and sesame gels were selected.

The hydrophobicity of the gels was compared by detecting the absorptivity and extraction efficiency of nonpolar androstenedione, testosterone, and progesterone, which are provable detected in wastewater and drinking water. Their quantification was made with micellar electrokinetic capillary chromatography (PF-MEKC).

The results showed that methanol was a perfect eluent for removing androstenedione and testosterone from cellulose acetate and hydroxypropyl cellulose modified gels. On the contrary, progesterone was extracted with high recovery from hydroxypropyl methylcellulose (HPMC) modified gels. However, the recoveries from lignin modified gels were very low. The highest recoveries were obtained with HPMC modified gels which were made of either frying or rapeseed oil. Lignin containing gel materials were hydrophilic and therefore nearly all get moist from water. 2 3 4 5 6 57 8 9 60 


\section{Introduction}

Generally, microemulsions (MEs) are composed of surfactant, water, oil, and alcohol. They have numerous advantages that have gained a lot of attention, especially, being as potential carriers of effective compounds in drug delivery [1-3]. Since MEs are isotropic, thermodynamically stable oilin-water $(\mathrm{o} / \mathrm{w})$ systems, they contain micro sized oil droplets or they have continuous structures $[4,5]$. Microemulsions are frequently transformed into complex semi-solid systems with the use of thickening agents, such as polymers [6-9], low-molecular weighed organic compounds [10], and/or inorganic compounds [11]. An example of synthetizing that kind of gels is to use caprylocaproyl polyoxyl-8-glycerides, diethylene glycol monoethyl ether, and propylene glycol monolaurate. For enhancing its viscosity, carbopol was used, since it formed ME-based gels [12]. Commonly, gels made of surfactant, co-surfactant, water, and oil can be formed to advanced products that are useful in pharmaceutical industry due to their feasibility as drug carriers [13-15]. Especially, the amount and types of gels exploited in biotechnology and food industry have grown greatly [16].

In analytics, specific gels are needed to separate biological macromolecules, such as proteins and lipoproteins, by planar or capillary electrophoresis techniques [17]. In gel-aided separations, electric field is used for generation of molecule movement that is depended on molar mass, length, conformation, hydrophobicity, and charge. Those molecular parameters influence in the permeability and compatibility in gel environment [18,19].

When gel formation is processed in water, hydroxyethyl cellulose and/or polyvinyl pyrrolidone may be added into solutions to make the material more hydrophobic [20]. Evidence is published about active bio-based nanomaterial films from fish gelatin and chitosan nanoparticles have shown to incorporate with oregano essential oil (Origanum vulgare L.). Then, chitosan particles were obtained by ionic gelation with sodium tripolyphosphate to have a spherical morphology (size $40-80 \mathrm{~nm}$ ) [21]. In addition, tensile and water vapor barrier properties of that kind of nanomaterial films showed to vary depending on concentration of essential oil used. Moreover, gelatin from partial hydrolysis of 
collagen is well-known for its good film-forming characteristics that leads to the formation of transparent and flexible films [22]. However, due to their hydrophilic nature, the films have poor water-vapor barrier [23] and cannot be used for extraction for environmental purposes, since the gel materials need to have hydrophobic properties to be suitable for cleaning of organic contaminants in water.

Until now, vegetable oil gels have not been used as solid materials in analytics. However, in literature there are examples of using vegetable oils as part of microemulsions. Mint oil ME has been used in dynamic light scattering (DLS) and electron paramagnetic resonance (EPR) studies, and citrus oil and eucalyptus oil ME in general analytics [24-26]. Modifiers like the surfactant of Brij-30 was needed to enable steroids to absorb through skin [27]. In addition, oil isolated from soya beans has been promising in studies with lecithin as the analysis medium [27].

Our group has earlier published results made with capillary electrophoresis using ME electrolytes made of vegetable oils for separation of isoflavonoids, benzodiazepines, steroids, and proteins $[28,29]$. Since the vegetable oils are heterogeneous, being non-polar and/or polar and containing triglycerides, they are mixtures of fatty acids, esters of glycerol, and fatty acids [30].

The ratio of various fatty acids varies between vegetable oils [29]. Typically, saturated fatty acids are preferred in gel formation, like palmitoleic and stearic acids in olive, walnut, and linseed oils. The quantity of cis-9-octadecanoic acid (18:1) in rapeseed, olive, walnut, and linseed oils are ca. 32, 84, 17, and $19 \%$. In ME capillary electrophoresis, the electrolyte made of linseed, walnut, olive, and rapeseed oils in steroid separation showed good efficiency $[28,29]$. In unsaturated vegetable oil the structural and rheological properties have an influence in gel formation and the quantity of the gel product [30]. According to literature, only $0.5 \%(w / w)$ of 12-hydroxy-9-trans-octadecenoic acid has been extracted from oils to gels [31]. The small extractability is not a problem, since in case of rapeseed, sesame, and diacylglycerol oils they show to influence the synthesis only, when the acid concentration is low [31-33]. Structure-function studies have shown that carboxyl groups, positions 
111 of hydroxyl groups, and lengths of acyl chains play the most important roles in gelation [34].

112 Although, triglyceride-based vegetable oils are important for polymer synthesis, vegetable oils and 113 their modifications are the raw materials for resin preparation. Furthermore, linseed and Tung oil 114 have been used for coating ingredients in oil paints and varnishes [35].

115 The present study was made with vegetable oils of macadamia, linseed, olive, walnut, frying, 116 rapeseed, sesame, and coconut oils synthetized with polyacrylamide and mixed with celluloses, 117 cotton, or Kraft lignin. Consequently, only three selected oil gels have fast gelation and therefore, 118 their performance in purification of steroid in water were studied. The steroid concentrations in the 119 eluates obtained from the extraction procedures were determined with partial filling micellar 120 electrokinetic capillary chromatography (PF-MEKC) with UV detection.

\section{2. Experimental}

\subsection{Chemicals}

123 The commonly detected steroids in wastewater were used as the analytes of the study. Androstenedione $\left(\mathrm{C}_{19} \mathrm{H}_{26} \mathrm{O}_{2}\right.$, purity $\left.\geq 98 \%\right)$, testosterone $\left(\mathrm{C}_{19} \mathrm{H}_{28} \mathrm{O}_{2}\right.$, purity $\left.\geq 98 \%\right)$, and progesterone $\left(\mathrm{C}_{21} \mathrm{H}_{30} \mathrm{O}_{2}\right.$, purity $\left.\geq 98 \%\right)$ were purchased from Sigma-Aldrich (Germany). They were used as received, and stored in a dark cold room $\left(-20^{\circ} \mathrm{C}\right)$. Ammonia (min. purity $25 \%$ ) from VWR International S.A.S (France) and ammonium acetate (purity 98\%, AA) from Sigma-Aldrich (Germany) were purchased for the electrolyte solutions in capillary electrophoresis. Methanol (HPLC-MS grade) was from Fisher Scientific (UK). The sodium salt of taurocholic acid monohydrate (BioXtra, purity $\geq 95 \%$ ) and sodium dodecyl sulphate (purity 99\%) were from Sigma-Aldrich 131 (Germany). Hydrochloric acid (1.0 M) and sodium hydroxide (1 M) were purchased from Oy FFChemicals Ab (Finland). Methanol (HPLC-MS grade) was used as the solvent in standard mixtures and as the eluent in SPE extracts. It was also used the marker of electroosmosis.

134 For gel formation extra pure vegetable oils used were rapeseed, olive, linseed, and walnut oils. The 
C20:0, C16:1, C18:1, C20:1, C22:1, C18:2, and C18:3. The rapeseed oil was manufactured by AOR N.V. (Belgium) and VitaD’or (Germany), olive oil by Sovena Group (Spain), linseed oil by Elixi Oil Oy (Finland), and walnut oil by Princes Foods B.V. (The Netherlands). Rapeseed oil had approved the acquisition of Belgian vegetable oil distributor AOR NV by U.S. grain trader in 2015 . The extra virgin olive oil from Slovenia was classified by UNESCO as Intangible World Heritage since 2013. Elixi Oy is company specialized in production of cold pressed flaxseed oil under oxygen-less environment. Walnut oil was achieved from Lanfranchi, (Italy), macadamia oil from Olivado (Australia), frying oil (mixture of sunflower, palm, and rapeseed oils), sesame oil from Lanfranchi (Princes Foods, B.V., The Netherlands), and coconut oil from Coconut Oil (UK).

Sesame oil has linoleic acid, oleic acid, palmitic acid, and stearic acid at 41\%, 39\%, 8\%, and 5\%, respectively (https://en.wikipedia.org). Rapeseed oil has the acids at $21 \%, 61 \%, 4 \%$, and $2 \%$ concentrations, and frying oil at 3.5-21\%, 55-83\%, 7.5-20\%, 0.5-5\%, respectively.

Tris(hydroxymethyl) aminomethane (Tris) and sodium tetraborate decahydrate (Borax) were purchased from Sigma-Aldrich (Germany). Ammonium persulfate (APS), acrylamide (AA), and bisacrylamide (N,N'-methylene-bisacrylamide) were from Merck (Darmstadt, Germany). Tetramethylenediamine (TEMED) was from Thermo Fischer Scientific Oy (Vantaa, Finland). Lignin (alkali, Kraft, pH 10.5), cotton, cellulose acetate (CA), hydroxypropyl cellulose (HPC), and hydroxypropyl methylcellulose (HPMC) were from Sigma-Aldrich (Germany).

Ultrapure water (MQ) was purified with a Direct-Q UV Millipore water purification system (Millipore S.A., Molsheim, France, $18 \mathrm{M} \Omega, \mathrm{pH}$ 5.80).

\subsection{Instruments and methods}

\subsubsection{Capillary electrophoresis and methods}

A Hewlett-Packard 3D CE instrument (Agilent, Waldbronn, Germany) equipped with a photodiode array detector (190-600 nm) was used for the determination of the steroids in the extracts and eluates. The CE instrument was applied with ChemStation programs (Agilent) for instrument running and 
161 data handling. Bare fused silica capillaries (i.d. $50 \mu \mathrm{m}$, o.d. $375 \mu \mathrm{m}$ ) were purchased from Polymicro

162 Technologies (Phoenix, AZ, USA). They were cut to the total length (Ltot) of $80 \mathrm{~cm}$ with the efficient 163 length (Leff) of $71.5 \mathrm{~cm}$. Before use, they were conditioned by sequentially flushing with $0.1 \mathrm{M} \mathrm{NaOH}$, 164 MQ water, and the electrolyte solution for $20 \mathrm{~min}$ each at 13.634 p.s.i. (940 mbar). Additionally, 165 before each analysis, the capillary was flushed with $0.1 \mathrm{M} \mathrm{NaOH}$ and the electrolyte solution for 2 $166 \min$.

167 The analysis method [35] was based on partial filling micellar electrokinetic chromatography (PF168 MEKC) with direct UV detection. The temperature during the analyses was $+25^{\circ} \mathrm{C}$. Positive polarity 169 at constant voltage $25 \mathrm{kV}$ was used in the measurements. The electrolyte solution in PF-MEKC gave $17017 \mu \mathrm{A}$ current. The analysis time was $20 \mathrm{~min}$, but the steroids migrated within $18 \mathrm{~min}$. The samples 171 were introduced into electrical separation at 0.50 p.s.i. ( $34.5 \mathrm{mbar}$ ) pressure for $6 \mathrm{~s}$. The pilot signals 172 in detection were 214 (for electroosmosis), 220 (for matrix profiling), and $247 \mathrm{~nm}$ (for steroids).

\subsubsection{Electrolytes in capillary electrophoresis}

174 The steroids in the extracts from gel filled tubes in SPE treatment were studied with partially filled 175 micelle mixture in basic $20 \mathrm{mM}$ ammonium acetate solution [36]. Its $\mathrm{pH}$ was adjusted to $\mathrm{pH} 9.68$ 176 with $25 \%$ ammonia. The micelle solution used in partial pseudo stationary phase was made by mixing $1771000 \mu \mathrm{L}$ of $20 \mathrm{mM}$ ammonium acetate (AA), $440 \mu \mathrm{L}$ of $100 \mathrm{mM}$ sodium dodecyl sulphate (SDS) in $17820 \mathrm{mM} \mathrm{AA}(\mathrm{pH} 9.68$ ), and $50 \mu \mathrm{L}$ of $100 \mathrm{mM}$ sodium taurocholate, in this specific order. The micelle 179 and the electrolyte solutions were sequentially introduced into the capillary in order to have the 180 micelle plug between the BGE solution and the standard or the SPE extracts. After the injection step 181 the capillary was dipped into BGE for 0.5 min before starting the analysis.

\section{$182 \quad$ 2.2.3 Preparation of ME gels}

183 The ME gels were prepared from macadamia, linseed, olive, walnut, frying oil (used for cooking and 184 analogues pure unused oil), rapeseed, sesame, and coconut oils (Supplementary data: $2 S$ 185 Experimental) according to the schemes informed in Figure 1. Hydrolysis of the vegetable oils were 
made at aqueous basic solution in both cases at ambient temperature (recipes 1 and 2) at ambient temperature before adding other solutions. When used in solid phase extraction, the oil gels (1.00 g, Supplementary data: Figure 2S) were mixed with lignin, cellulose acetate (CA), cotton, hydroxypropyl cellulose (HPC), or hydroxypropyl methylcellulose (HPMC) (100 mg, 10\% of the weight of the oil gel) to stand mechanical stress in packing the material into tubes and against the vacuum during the SPE treatment. The gel formation process was similar to that making PA-type gels, but with the exception that sodium dodecyl sulphate (SDS) was replaced by the vegetable oils.

The solutions used were $50 \mathrm{mM}$ sodium tetraborate (STB) buffer (pH 8.5), acrylamide solution (AA, $\geq 99 \%$, HPLC grade) at $30 \%$ aqueous solution (w/v), $3.9 \mathrm{M}$ ammonium persulphate (APS) solution, and tetramethylethylenediamine (TEMED). The $1.5 \mathrm{M}$ tris(hydroxymethyl) aminomethane (Tris, $\mathrm{pH}$ 8.8) solution was prepared into MQ-water for gel synthesis.

\subsubsection{Solid-phase extraction}

The SPE device Vac Master (Biotage VacMaster 20 Sample Processing Station) was used for solid phase extraction of the water samples. The ME gels (1.00 g or when liquid 3 x $200 \mu \mathrm{L})$ added by 100 mg of CA, cotton, HPMC, HPC, or lignin) were placed onto deactivate cotton membrane. In the final studies only frying oil, rapeseed oil and sesame oil based gels were used, since they had the fastest gelation process and thickening performance.

Totally 250 oil gel material including the carbohydrate modified materials were used in the SPE extraction. The steroid sample mixtures in the studies were prepared to $5 \mu \mathrm{g} / \mathrm{mL}$ concentration (15.5 $\mu \mathrm{M}$ androstenedione, $17.3 \mu \mathrm{M}$ testosterone, and $15.9 \mu \mathrm{M}$ progesterone) in water.

\subsubsection{Preparation of samples}

The stock solutions of the steroids were $1000 \mathrm{mg} / \mathrm{L}$. The water samples in the SPE contained $5 \mathrm{mg} / \mathrm{L}$ of the steroids. The compounds removed from the gel material during the extraction into methanol. The water parts were also analyzed and therefore they were concentrated by removal of the solvent. 
210 First, the eluates were evaporated to dryness at $40{ }^{\circ} \mathrm{C}$ temperature under nitrogen. Then, the 211 precipitates were dissolved into $300 \mu \mathrm{L}$ of methanol. The whole solution was put into a $250 \mu \mathrm{L}$ vial. 212 3. Results

213 Vegetable oils used in preparation of gels have noticed to improve properties of the new preparations and have shown to exploit them in novelty valued applications [31,32]. In the present research, vegetable oil ME gels were prepared for removing hydrophobic steroids from water. All layers in gel formation (Figure 1), which were the upper fraction from the vegetable oil, the middle layer from oil-in-water $(\mathrm{o} / \mathrm{w})$, and the lower fraction from water, were used for the studies. The gels as such could be spread to film format (Supplementary, Figure 3S) and used in gel electrophoresis for protein separation (Supplementary, Figure 4S). When they were used for the targeted water cleaning, the gel durability against mechanical pressure needed to be increased. Therefore, they were mixed with bio materials such as Kraft lignin, cotton, cellulose acetate (CA), hydroxypropyl cellulose (HPC), and hydroxypropyl methylcellulose (HPMC). Then, the gels could be used to remove of nonpolar steroids from water. The steroids were selected as the analytes, since they are found in wastewater and drinking water $[36,37]$. Furthermore, the steroids were markers to follow the behaviour of the gel materials and compare them with each other.

\subsection{Behaviour of the gel materials for extraction}

Eight different gels from macadamia, linseed, olive, walnut, rapeseed, sesame, coconut, and frying oils (Figure 1; Supplementary data: Table 1S, Figure 1S) were used. Differences in their chemical behaviour was observed due to the saturation state of the fatty acids. Frying oil was included in the study, since it has been scientifically pointed that frying oil that is made of olive oil, has equal or superior properties compared with the refined vegetable oil [38]. In the present study, the frying oil contained sunflower, palm, and rapeseed oils. Its behavior was not previously known. After modification with lignin, cotton, or celluloses hydrophobicity of all synthetized gels was changed compared to the basic materials. The present study showed that the most decrease in hydrophobicity 
235 was obtained with lignin, because it was from alkali Kraft process ( $\mathrm{pH}$ 10.5). On the other hand, the 236 most increase in the hydrophobicity was observed after HPMC modification of any bio gel. Recent 237 literature supports the observations, since oregano oil has noticed to increase the hydrophobicity of 238 bioactive materials that were made of fish gelatine and chitosan [21].

239 The strong hydrophobic character of the gels was important since using them for cleaning of 240 contaminants from water. In the present work, hydrophobicity, wettability, and floating properties of 241 the selected gel mixtures were studied by observations with water repulsion of the gel materials. The 242 differences between the ME gels were studied using experimentally measured total steroid 243 concentrations from methanol extract by comparing them with the concentrations in water 244 concentrate. The gels from macadamia, linseed, walnut, and coconut were also used in the 245 examination, but they were excluded from the final studies (Supplementary data: Figures 5S, 6S, 7S, 246 and 8S). The reasons were their low recoveries in extraction, quite high matrix effect in 247 electrophoretic separation, and especially, the very slow gel formation at ambient temperature (Figure $2481)$.

$249 \quad 3.2$ Determination of steroids with capillary electrophoresis

250 For the gel studies, the PF-MEKC method was optimized at $247 \mathrm{~nm}$ UV-wavelength in determination 251 of the steroids. It was recently used for analyses of eight steroids in wastewater and drinking water 252 samples $[36,37,39,40]$. In the earlier studies, the steroids were isolated from authentic water with 253 commercial nonpolar polymer-based SPE materials. In the present study the water samples were 254 artificially prepared, since the behaviour of the gel materials were studied. Usually, the steroids are 255 at very low concentrations (pg/L-ng/L) in environmental water, although in emission sources the 256 concentrations may be 1000-100000 times higher [39]. Using the PF-MEKC method in CE, UV 257 detecting of the steroids needs concentrations above $0.1 \mathrm{mg} / \mathrm{L}$. According to literature it means that 258 the sample volumes should be $2 \mathrm{~L}-5 \mathrm{~L}$ to enrich the steroids for the PF-MEKC analyses [36]. Thus, 
259

standard samples were used to evaluate the advantages and differences of the gels without unknown effects from other biological matrices except the gel components.

Figures 2 and 3 show the ordinary steroid profiles from the water eluates from the o/w phase gels made of sesame oil modified with CA, frying oil with Kraft lignin, and sesame oil gel containing HPMC. It was noticed that in case of lignin modification the eluates gave always a baseline that was 10 times higher than that obtained in presence of HPMC. The reason was the matrix that reached the UV detector in six minutes and showed a high absorption thereafter. Since all the oils used contained linoleic acid, oleic acid, palmitic acid, and stearic acid, it could be supposed that the alkyl chains of the oil structures would give rather specific than similar gel properties that could be detected from the individual electropherogram.

Based on the electrophoresis profiles of water (Figures 2 and 3) the migration order of the target compounds was androstenedione, testosterone, and progesterone. The figures also show that the water eluates contain less matrix compounds than the correspondingly obtained methanol extract (Figure 4). Even though, the sensitivities of the steroids were higher in methanol than in water extracts.

The concentrations of androstenedione, testosterone, and progesterone were used to calculate the lipid absorptivity of frying, rapeseed, and sesame oil gels (Figures 2, 3, and 4). In all cases, the steroid profiles were identified by spiking with a mixture of $2 \mu \mathrm{g} / \mathrm{mL}(6.98 \mu \mathrm{M}$ androstenedione, $6.93 \mu \mathrm{M}$ testosterone, and $6.36 \mu \mathrm{M}$ progesterone) concentration to justify correctness of their migration. Concentration calibration was made with $0.5-10.0 \mu \mathrm{g} / \mathrm{mL}$ solution mixtures by resulting in the ranges of $1.75-35.0 \mu \mathrm{M}$ for androstenedione, $1.73-34.6 \mu \mathrm{M}$ for testosterone, and 1.59-31.8 $\mu \mathrm{M}$ for progesterone. The corresponding calibration lines were $y=0.632 x-0.029(r 20.940), y=0.779 x-0.213$ (r2 0.962), and $y=4.315 x-4.077$ (r2 0.968). Therefore, the limits of detection (LOD) were $1.75 \mu \mathrm{M}$, $1.30 \mu \mathrm{M}$, and $0.35 \mu \mathrm{M}$ and the quantification limits (LOQ) $5.25 \mu \mathrm{M}, 4.00 \mu \mathrm{M}$, and $1.02 \mu \mathrm{M}$, respectively. 
283 Steroids adsorbed onto frying oil-based ME gels were better removed to methanol than to water. In 284 presence of Kraft lignin methanol was as good eluent as water (MQ water, pH 5.80) for steroid 285 release. All of the most hydrophobic HPMC modified vegetable oil-based gels were very selective 286 for methanol elution. Figure 5 shows the results that were more centralized in steroid extracts from 287 frying oil gel than from sesame oil gels. It can also be concluded that Kraft lignin modification was 288 not selective enough to clean the water samples from steroids, since those gels absorb water. 289 Especially, when Kraft lignin was mixed to rapeseed oil gel that was originated from the upper phase 290 of the synthesis (Figure 1), PF-MEKC analyses gave identically small recoveries from extraction of 291 steroids with both methanol and water. Similarly, the similar type small peaks with low 292 concentrations could be obtained in both CA and HPC modified rapeseed oil from the middle (o/w) 293 phases due to the low yields of steroids from those materials.

294 Figure 6 shows the results of steroids extracted from rapeseed, sesame, and frying oil gel materials. 295 The Figures 6A and B show the compilation of the results in CA, cotton, and HPC modified gels with 296 adsorbed steroids. It can be seen that methanol and water in elution had nearly equal selectivity jointly 297 with the w/o emulsion fractions (Figure 1, middle). On the contrary, HPMC or Kraft lignin 298 modification was more suitable for removing steroids from water combined with all the oil layers 299 (upper) in methanol elution. The more nonpolar the gel, the longer the steroids retained. Thus, in 300 those cases methanol was particularly selective for the steroid extraction. The analyte recoveries from nonpolar phases were $70-85 \%$ for all the steroids. This was in accordance with our earlier studies [36,37]. The obtained recoveries were also comparable with the study on extraction of diclofenac 303 formulation with ME gel made of caprylocaproyl polyoxyl-8 glycerides, diethylene glycol monoethyl 304 ether, and propylene glycol monolaurate allowing the recoveries of $77 \%$ and $70 \%$ [12].

305 In the presence of Kraft lignin, CA, and cotton as the gel modifiers the results of the extracts were more centralized than in using nonpolar HPC and HPMC modification. The hydrophobicity and the 
308 [41], as is visualised also in Figure 6. It shows that the analytes were merely detected from the upper 309 (oil) and middle (o/w) layers in nonpolar HPMC modified oil gels (Supplementary data: Figure 10S).

\subsection{Water resistance of the gels}

Polar groups and ionization of the gel mixtures decreased their hydrophobic character. The decrease of hydrophobicity of gels modified with Kraft lignin, cotton, and celluloses gave the order of lignin $>$ cotton > cellulose acetate $>$ HPC $>$ HPMC. When the additives had a role in the wettability of the gels, they could be detected by sinking to the bottom of the water container. Those materials that could be floating spread slightly out in presence of water. Then, the best material combinations with similar floating properties as the two best water resistant were CA and HPMC modified rapeseed, frying, and sesame oil based gels, but also lignin modified rapeseed and sesame oil gels. All CA and HPMC based gels and a few Kraft lignin based, some of cotton modified, and a few HPC modified gels were floating more than 5 days, 120 h, 120 h, and 2 h, respectively (Figure 7).

On the contrary, gels made from rapeseed and sesame oils, and finalized with lignin and cellulose acetate, became hydrophobic and thus they could not absorb water (Figure 7). The similar effect was generated, when the ingredients were rapeseed, sesame, and frying oils modified with HPMC or CA. Frying oil and alkali Kraft lignin ended up to hydrophilic gels, and sank immediately below the water surface (Supplementary data: Figure 9S). It was recognized that hydrophilic lignin had a significant role in wettability. Similarly, frying oil gels modified by cotton resisted water only less than a minute before absorption and gone down into water. However, CA and HPMC in rapeseed, sesame, and frying oil gels enhanced the material hydrophobicity accomplishing lightweight materials.

The PF-MEKC-UV studies showed that the highest peak areas correlating to the highest concentrations and recoveries were obtained for androstenedione and testosterone in methanol extracts from CA and HPC modified gels. In that case, the extraction properties were high, although HPC modification was not very practical due to the poor floating properties. On the contrary, the largest recoveries for progesterone were obtained in both methanol and water, when the gels were 
modified with HPMC. Unfortunately, the peak areas of androstenedione were the smallest, which showed that water was not a good eluent and the steroid retained on the HPMC containing gels. The smallest recoveries were observed in water extracts for both testosterone and progesterone in lignin modified gels (Supplementary data: Figure 9S).

To compare the gels by extraction properties, the best vegetable oil based gel was rapeseed oil, since in the presence of HPMC the gel gave the best recoveries for all steroids. Furthermore, frying oil from upper phase (Figure 1) had excellent absorptivity against the lipid steroid and also verified its floating capability on water surface. The worst material for extraction of steroids was CA modified from the lower phases of frying, sesame, and rapeseed oils.

The study showed that vegetable oil based gels can be used to isolate steroids from water matrix. In addition, the selected eluents in SPE showed that the recoveries were high. Nearly all steroids could be removed from the sorbent to enable their reusability.

\section{Conclusions}

The study shows that the gels made of vegetable oils and modified with Kraft lignin, cotton, and cellulose related substances are capable to adsorb nonpolar steroids from water. When the oil gel materials are not sank in water, they may be used for water pretreatment to collect nonpolar compounds, like steroid-type compounds and other lipids from surface water. Capillary electrophoresis techniques showed to work excellent for comprehensive profiling of the steroids after solid phase extraction enrichment made by the new oil gels.

\section{Acknowledgements}

Magnus Ehrnrooth foundation (in 2015-2017 to S.E.) is acknowledged for the financial support. The authors declare that they do not have competing financial interest concerning the project. They do not have any conflicts either.

\section{References}

[1] A. Froelich, T. Osmałek, A. Snela, P. Kunstman, B. Jadach, M. Olejniczak, G. Roszak, W. Białas, Novel microemulsion-based gels for topical delivery of indomethacin: Formulation, physicochemical 
359 properties and in vitro drug release studies, Journal of Colloid and Interface Science 507 (2017) 323360336.

361 [2] M.J. Lawrence, G.D. Rees, Microemulsion-based media as novel drug delivery systems, Adv. 362 Drug Deliv. Rev. 64 (2012) 175-193.

363 [3] S. Talegaonkar, A. Azeem, F. Ahmad, R. Khar, S. Pathan, Z. Khan, Microemulsions: A Novel 364 Approach to Enhanced Drug Delivery, Recent Pat. Drug Deliv. Formul. 2 (2008) 238-257.

365 [4] D.J. McClements, Nanoemulsions versus microemulsions: terminology, differences, and 366 similarities, Soft Matter 8 (2012) 1719-1729.

367 [5] Y.S. Rhee, J.G. Choi, E.S. Park, S.C. Chi, Transdermal delivery of ketoprofen using 368 microemulsions. Int J Pharm 228 (2001) 161-170.

369 [6] A. Froelich, T. Osmałek, P. Kunstman, R. Roszak, W. Białas, Rheological and textural properties 370 of microemulsion-based polymer gels with indomethacin, Drug Dev. Ind. Pharm. 42 (2016) 854-861.

371 [7] M. El-Badry, G. Fetih, F. Shakeel, Comparative topical delivery of antifungal drug croconazole 372 using liposome and micro-emulsion-based gel formulations, Drug Deliv. 21 (2014) 34-43.

373 [8] B. Rozman, A. Zvonar, F. Falson, M. Gasperlin, Temperature-sensitive microemulsion gel: an 374 effective topical delivery system for simultaneous delivery of vitamins C and E, AAPS Pharm Sci 375 Tech 10 (2009) 54-61.

376 [9] S. Miao, P. Wang, Z. Su. S. Zhang, Vegetable-oil-based polymers as future polymeric 377 biomaterials, Acta Biomaterialia, 10 (2014) 1692-1704.

378 [10] G. Feng, Y. Xiong, H. Wang, Y. Yang, Gelation of microemulsions and release behavior of 379 sodium salicylate from gelled microemulsions, Eur. J. Pharm. Biopharm. 71 (2009) 297-302.

380 [11] B. Rozman, M. Gosenca, M. Gasperlin, K. Padois, F. Falson, Dual influence of colloidal silica 381 on skin deposition of vitamins C and E simultaneously incorporated in topical microemulsions, Drug 382 Dev. Ind. Pharm. 36 (2010) 852-860.

383 [12] B. Hajjar, K.-I. Zier, N. Khalid, S. Azarmi, R. Löbenberg, Evaluation of a microemulsion-based 384 gel formulation for topical drug delivery of diclofenac sodium, Journal of Pharmaceutical 385 Investigation 48(3) (2018) 351-362.

386 [13] Y. Zheng, W.-Q. Ouyang, Y.-P. Wei, S. F. Syed, C.-S. Hao, B.-Z. Wang, Y.-H. Shang, Effects 387 of Carbopol ${ }^{\circledR} 934$ proportion on nanoemulsion gel for topical and transdermal drug delivery: a skin 388 permeation study, Int J Nanomedicine 11 (2016) 5971-5987.

389 [14] A. Spernath, A. Aserin, Microemulsions as carriers for drugs and nutraceuticals, Adv. Colloid 390 Interface Sci. 128-130 (2006) 47-64.

391 [15] I. Kirill, S.C. Roberge, O. Zabeida, M. Robert, J. E. Klemberg-Sapieha, J Mater Sci: Mater Med $39220(2009) 681-689$. 
393 [16] L.S. Nair, C.T. Laurencin, Polymers as biomaterials for tissue engineering and controlled drug 394 delivery. Adv Biochem Engin/Biotechnol 102 (2006) 47-90.

395 [17] J. Kopecek, Hydrogel biomaterials: a smart future? Biomaterials 28 (2007) 5185-5192.

396 [18] H. Omidian, K. Park, Hydrogels. In Fundamentals and Applications of Controlled Release Drug 397 Delivery. Edited J. Siepmann, R Siegel, M Rathbone. 2012. Springer New York, NY.

398 [19] J.H. van Esch, B.L. Feringa, New Functional Materials Based on Self-Assembling Organogels: 399 From Serendipity towards Design, Angew Chem Int Ed Engl 2000, 39: 2263-2266.

400 [20] U.A. Krut, A. Guevara, J. Huang, A.A. Shaposhnikov, A.I. Vezentsev, Method for preparation 401 of bioactive sorbent gel composition. Russ. (2017), RU 2616250 C1 Apr 13, 2017.

402 [21] S.F. Hosseini, M. Rezaei, M. Zandi, F. Farahmandghavi, Development of bioactive fish 403 gelatin/chitosan nanoparticles composite films with antimicrobial properties Food Chem. 194 (2016) $404 \quad 1266-1274$.

405 [22] M.B. Pérez-Gago, Protein-Based Films and Coatings, in Edible Coatings and Films to Improve 406 Food Quality, 2nd Ed. (Eds. A.E. Baldwin, R. Hagenmaier, J. Bai) 2012, pp.14-58. Taylor and Francis 407 Group, Boca Raton, USA, CRC Press.

408 [23] S.F. Hosseini, M. Zandi, M. Rezaei, F. Farahmandghavi, Two-step method for encapsulation of 409 oregano essential oil in chitosan nanoparticles: preparation, characterization and in vitro release 410 study. Carbohydr Polym. 95 (2013) 50-56.

411 [24] F. Zhong, M. Yu, C. Luo, C.F. Shoemaker, Y. Li, S. Xia, J. Ma, Formation and characterization 412 of mint oil/S and CS/water microemulsions, Food Chem 115 (2009) 539-544.

413 [25] M. Fanun, Properties of microemulsions with mixed non-ionic surfactants and citrus oil, Colloids 414 Surf. A: Physicochem Eng Aspects 369 (2010) 246-252.

415 [26] B. Biruss, H. Kählig, C. Valenta, Evaluation of a Eucalyptus Oil Containing Topical Drug. 416 Delivery System for Selected Steroid Hormones, Int J Pharm 328 (2007) 142-151.

417 [27] V. Papadimitriou, E.D. Tzika, S. Pispas, T.G. Sotiroudis TG, Xenakis A., Colloids Surf A: 418 Physicochem Eng Aspects 2011, 382: 232-237.

419 [28] H. Sirén, A. Karttunen, Microemulsion electrokinetic chromatography for the separation of 420 carbamazepine, oxcarbazepine, and their metabolites, J Chrom B 783 (2003) 113-124.

421 [29] H. Sirén, S. Vesanen, J. Suomi, Separation of steroids using vegetable oils in microemulsion 422 electrokinetic capillary chromatography, J Chrom B 945/946 (2014) 199- 206.

423 [30] A.J. Wright, A.G. Marangoni, Formation, structure and rheological properties of ricinelaidic 424 acid-vegetable oil organogels. J. Amer. Oil Chem. Soc. 83 (2006) 497-503.

425 [31] N. Karak, Vegetable Oil-Based Polymers: Properties. Processing and Applications, 2012. 426 Cambridge, UK, Woodhead Publ. (Elsevier Ltd). 
427 [32] Z.S. Petrovic, Polyurethanes from vegetable oils, Polym. Rev. 48 (2008)109-155.

428 [33] C Zhang, TF Garrison, SA Madbouly, MR Kessler, Recent Advances in Vegetable Oil-Based 429 Polymers and Their Composites. Progress in Polymer Science 2017, 71, 91-143.

430 [34] J. Daniel, R. Rajasekharan, Organo gelation of Plant Oils and Hydrocarbons by Long-Chain 431 Saturated FA, Fatty Alcohols, Wax Esters, and Dicarboxylic Acids. JAOCS 2003, 80(5): 417-421.

432 [35] M. Samadzadeh, S.H. Boura, M. Peikari, A. Ashrafi, M. Kasiriha, Tung oil: an autonomous 433 repairing agent for self-healing epoxy coatings, Prog. Org. Coat. 2011 70, 383-387.

434 [36] H. Sirén, S. El Fellah, Androgens, oestrogens, and progesterone concentrations in wastewater 435 purification processes measured with capillary electrophoresis, Environmental Science and Pollution 436 Research (2017), 24(20), 16765-16785.

437 [37] S. El Fellah, G. Duporté, H. Sirén, Steroid hormones, inorganic ions and botrydial in drinking 438 water. Determination with capillary electrophoresis and liquid chromatography-orbitrap high 439 resolution mass spectrometry, Microchemical Journal 133 (2017) 126-136.

440 [38] A. Chiou, N. Kalogeropoulos, Virgin Olive Oil as Frying Oil, Comprehensive Reviews in Food 441 Science and Food Safety 16 (2017) 632-646.

442 [39] H. Sirén, S. El Fellah, Steroids contents in waters of wastewater purification plants: 443 determination with partial-filling micellar electrokinetic capillary chromatography and UV detection, 444 International Journal of Environmental Analytical Chemistry 96 (2016) 1003-1021.

445 [40] S. El Fellah, H. Sirén, Recent Developments in Capillary Electrophoresis of Steroids and Sterols, 446 Journal of Biomedical Research and Practice 2(1) (2018) 1-21, Article ID: 100006.

447 [41] J.A. Queiroz, C.T. Tomaz, J.M.S. Cabral, Hydrophobic interaction chromatography of proteins. 448 J. Biotechnol. 87 (2001) 143-159 


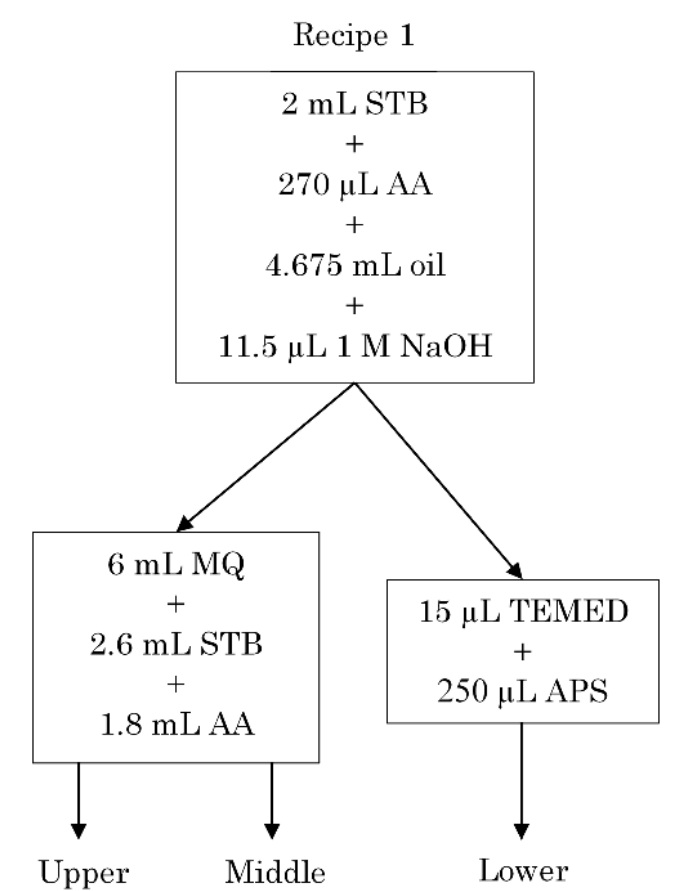

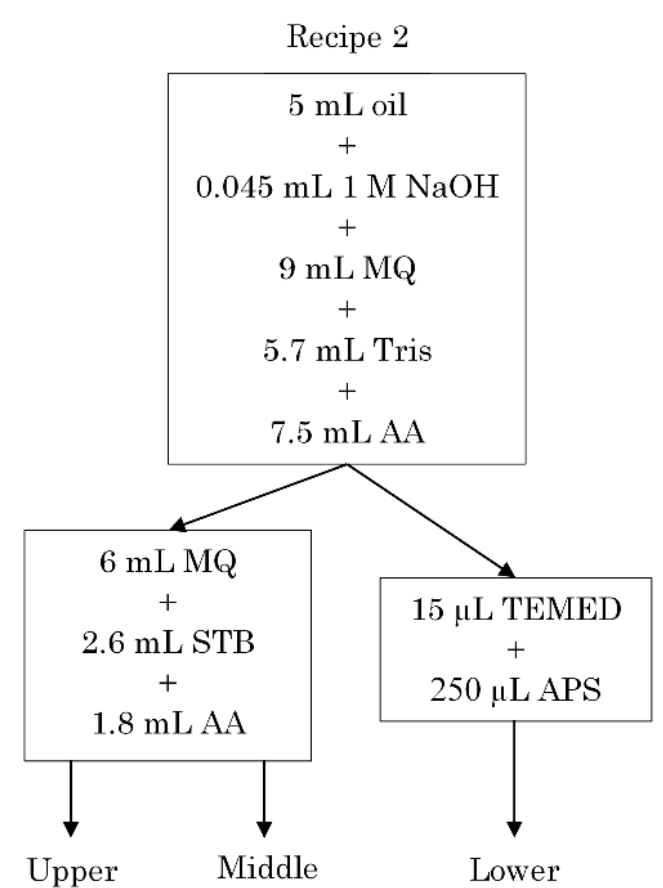

449

450

451

452

453

454

455

456

457

458

459

460

461

462

463

464

465

466

467

468

469

Figure 1. Procedures for synthesis of vegetable oil gels. All the phases (upper, middle, lower) for each vegetable oil were used in the study. The three layers contained mostly oil (upper), mixture of oil and water (middle), and water (lower). TEMED and APS were used for gelation of the water layer. Upper layer was oil phase, middle layer was water-in-oil/oil in water layer, and lower layer was water layer. The concentration and $\mathrm{pH}$ values of the buffers were optimized, since those parameters effected gelation. (1) 

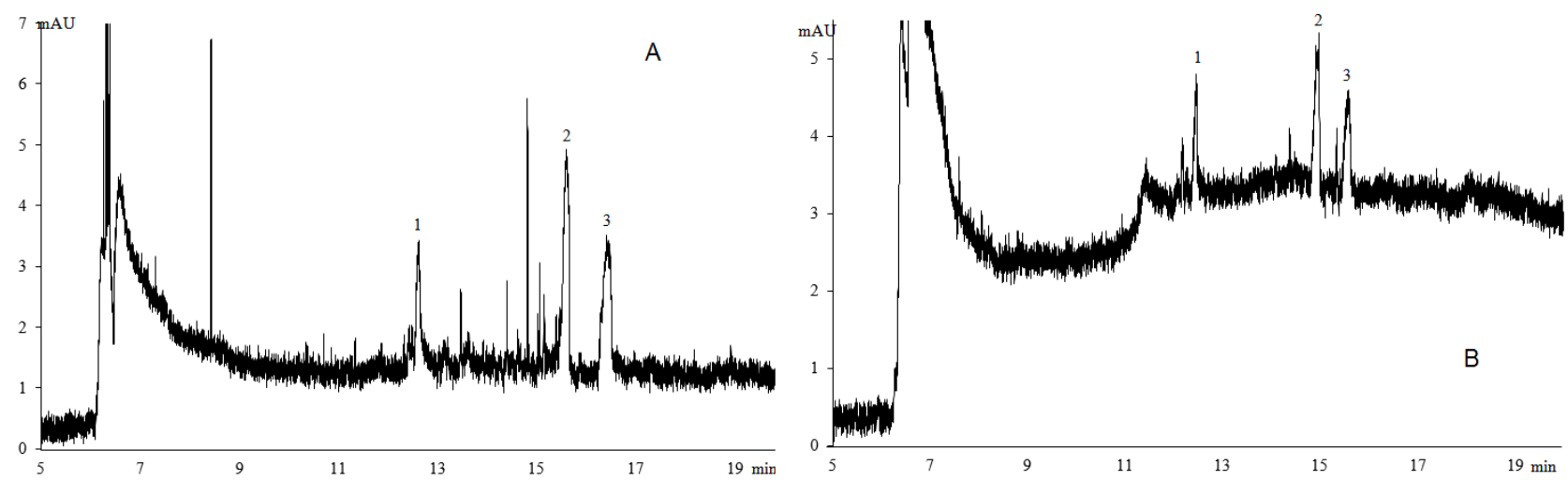

471

Figure 2. Electropherograms of water eluates of steroids. (A) Sesame oil-CA, middle phase from recipe 1 (Fig. 1); (B) Frying oil-lignin, middle phase from recipe 2 (Fig. 1). Separation conditions as explained in Experimental part. Peaks (1) androstenedione, (2) testosterone, (3) progesterone. Detection at $247 \mathrm{~nm}$. Method: PF-MEKC with ammonium acetate $(\mathrm{pH} 9.68)$ as the electrolyte and mixed micelle solution made of SDS and STC as the pseudo stationary phase. Volume in hydrodynamic injection was $55.67 \mathrm{~nL}$ (CE Expert Lite, SCIEX). Capillary dimensions: $80 \mathrm{~cm}$ (Ltot) and $71.5 \mathrm{~cm}$ (Ldet). 

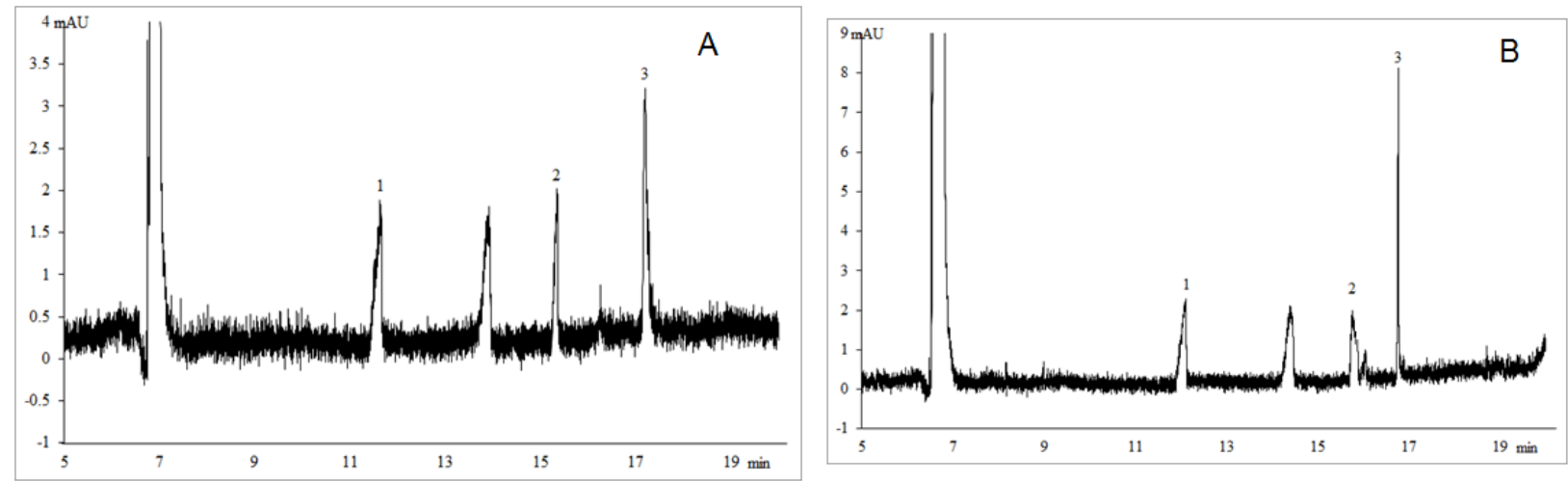

493 Figure 3. Electropherograms of eluates obtained with HPCM modified ME sorbents. (A) Canola oil gel and 494 (B) Frying oil gel. Elution was made with MQ water. Fraction is the middle phase from recipe 1 (Fig. 1). 495 Volume in hydrodynamic injection was $55.67 \mathrm{~nL}$ (CE Expert Lite, SCIEX). Capillary length $80 \mathrm{~cm}$.

496

497

498

499

500

501

502

503

504

505

506

507

508

509

510

511

512

513

514

515

516 


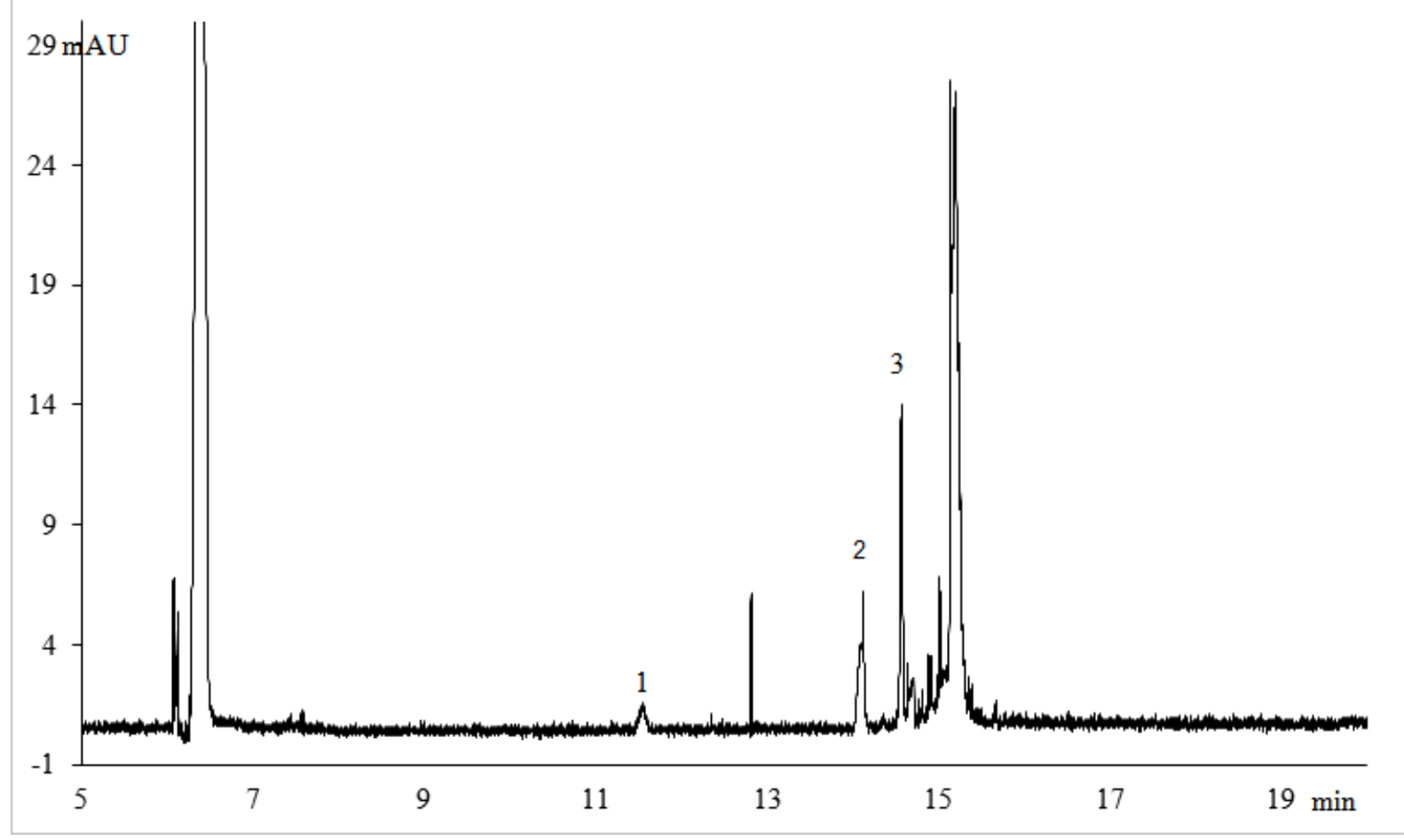

Figure 4. Electropherogram of the steroid profile obtained from SPE methanol made on HPCM modified sesame oil based gel, middle phase made by the recipe 1 . Methanol extract. Detection at $247 \mathrm{~nm}$. Other details as in Fig.2. Volume in hydrodynamic injection was $55.67 \mathrm{~nL}$ (CE Expert Lite, SCIEX). Capillary dimension were $70 \mathrm{~cm}$ (Ltot) and $61.5 \mathrm{~cm}$ (Ldet). 
Total peak area in steroid profile sum in methanol extract-sum in water extract

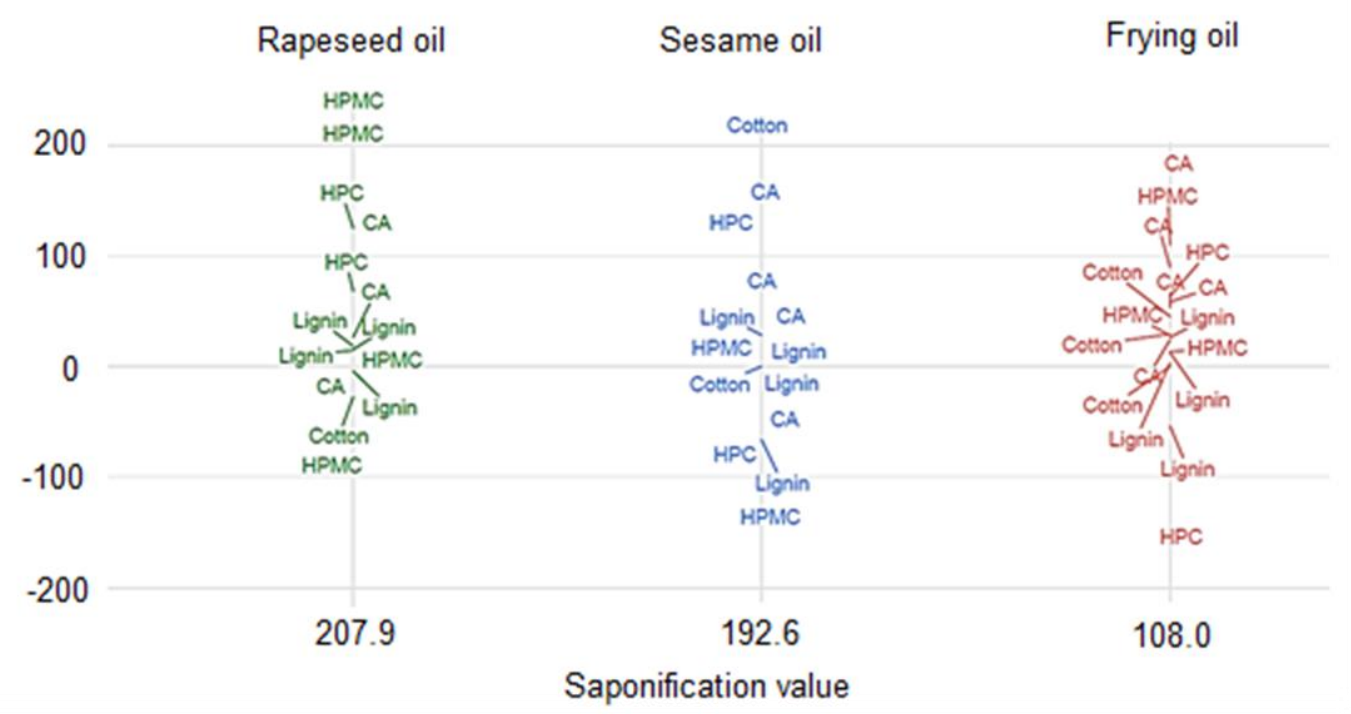

539

Figure 5. Statistical data from correlation of total peak areas of steroids in electropherograms measured with PF-MEKC from methanol and water extracts. SPE were made with canola oil, sesame oil, and frying oil gels modified with HPCM, HPC, CA, cotton, and lignin. The total peak areas were calculated from the steroid profile in the electropherogram from sum of peaks in methanol extract subtracted by the sum of those peaks in water extract. Analysis conditions as in Figure 2. Zero-level correspond equal total concentrations in methanol extract and water extract. 
Total peak area in steroid profile sum in methanol extract-sum in water extract

3

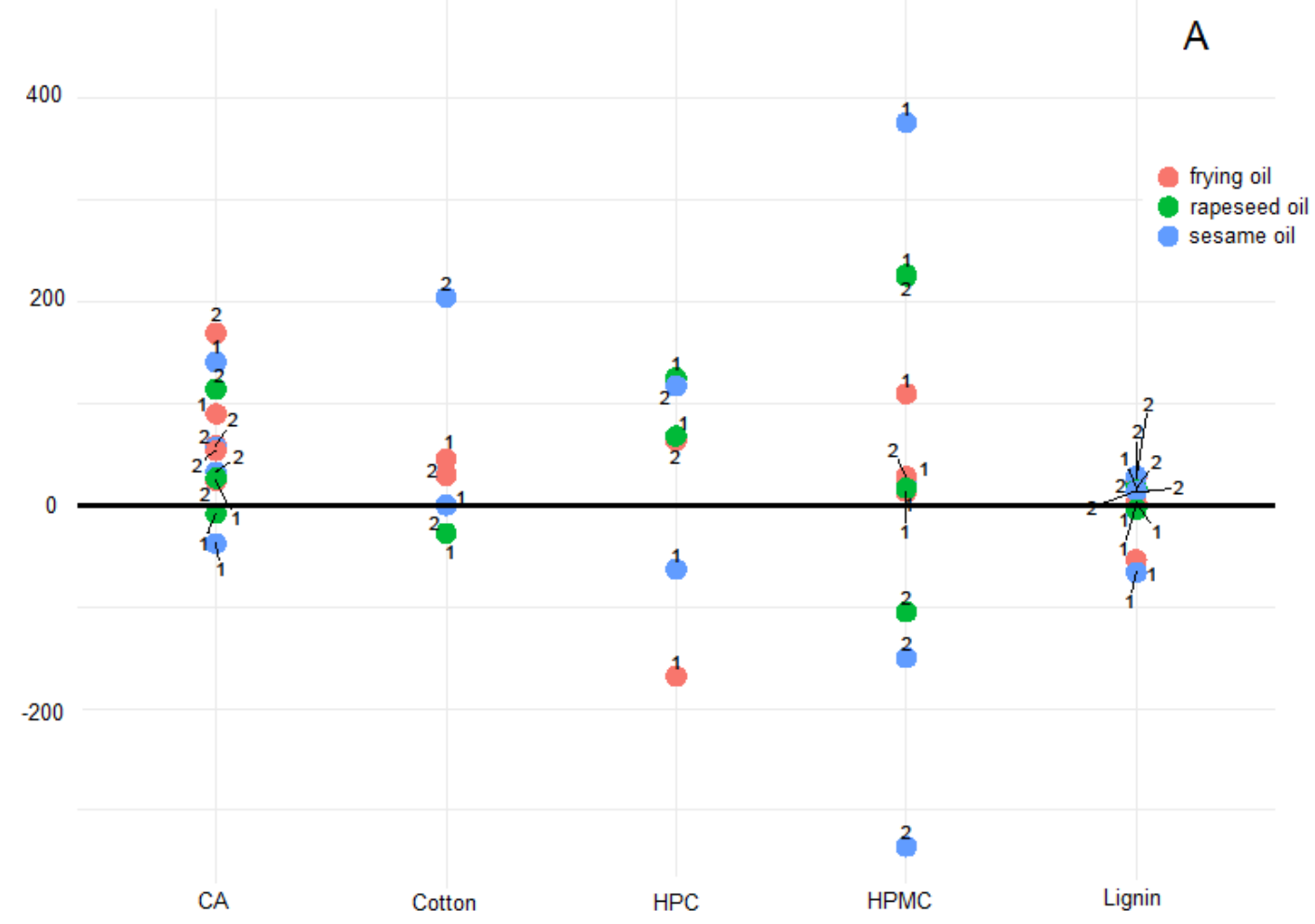

559

Total peak area in steroid profile

sum in methanol extract-sum in water extract

Upper

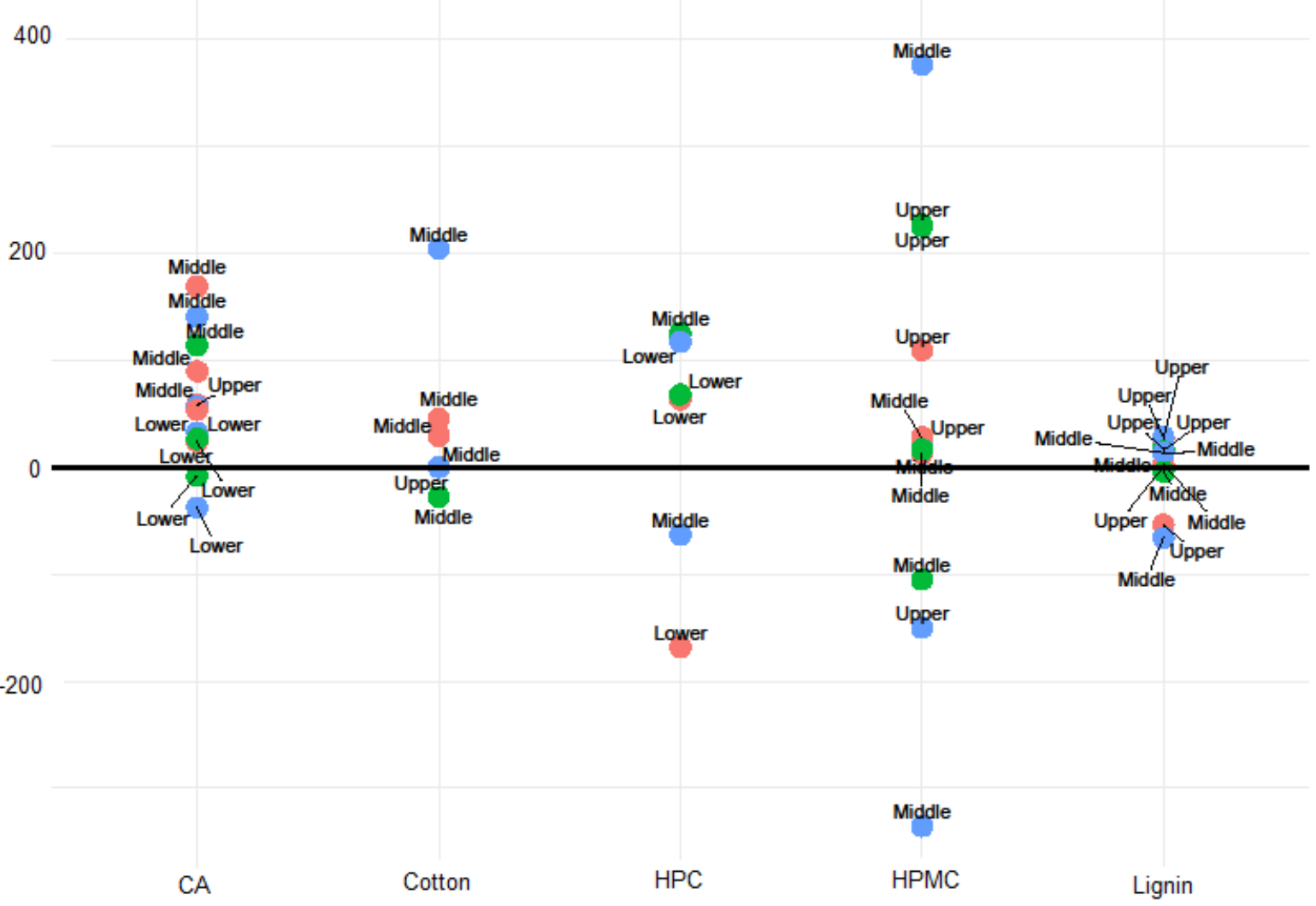


562 Figure 6. Comparison of methanol and water solvents in extraction of steroids from cellulose, cotton, and 563 lignin modified ME gels. (A) Numbers 1 and 2 present the recipes used for the synthesis (Figure 1); (B) 564 upper, middle, and lower present the phases obtained with ME gel formation. Analysis conditions as in 565 Figure 2. The colours in the figure $A$ and $B$ represent the same vegetable oil. The spots in the figures $A$ and 566 B represent the same phases made with the individual recipe. The spots below the horizontal line mean 567 that the steroids are extracted with water from the gels. Those above the line mean that the steroids are 568 extracted with methanol. 


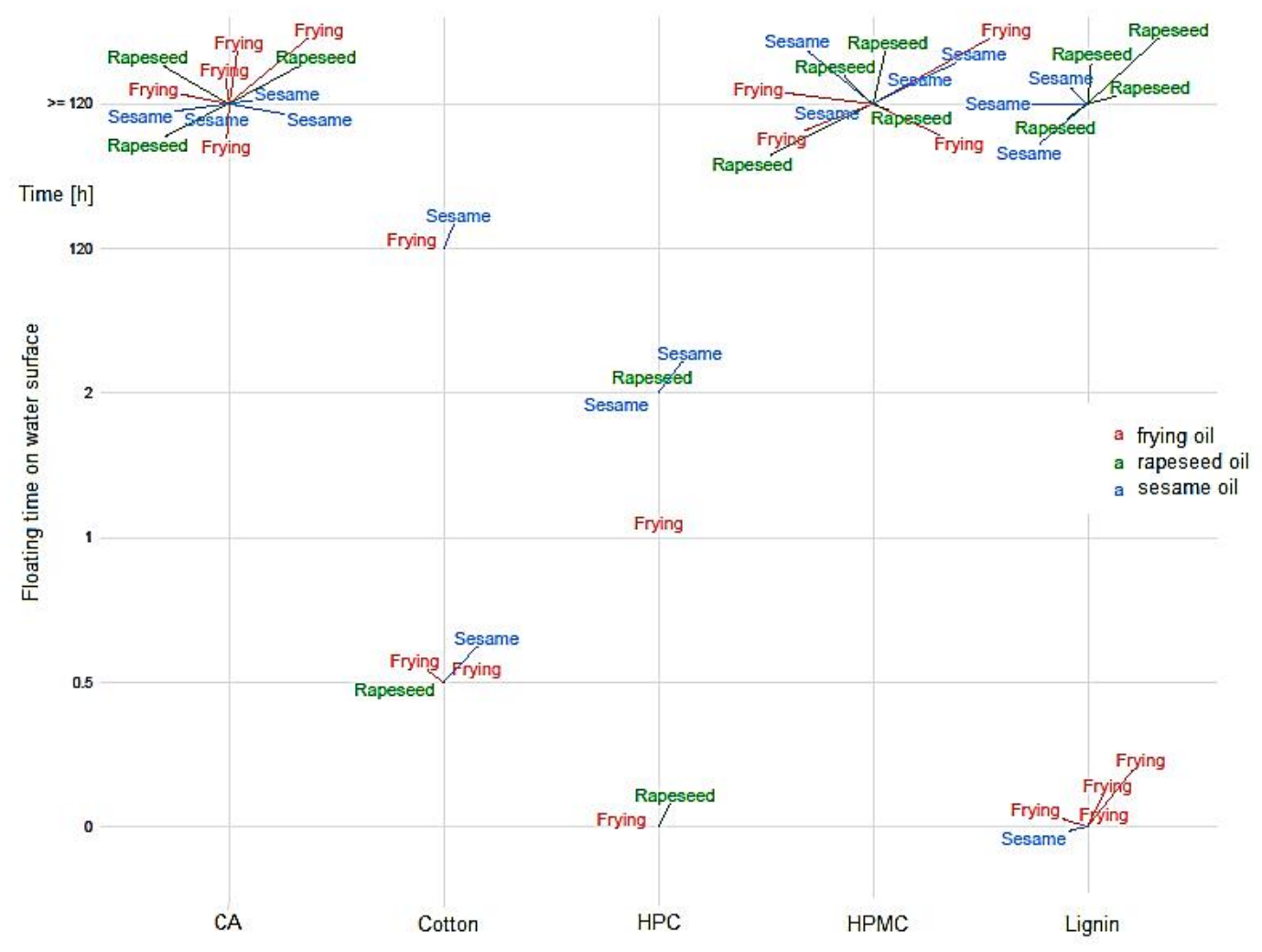

598 Figure 7. Comparison of floating properties of the ME gels modified with celluloses, cotton, and lignin. The

599 ME gels studied were made with recipes 1 and 2. Upper, middle, and lower phases were studied. Selected 600 data from PF-MEKC -UV analyses were used to clarify the differences. The analysis conditions are informed 601 in Figure 2.

602 